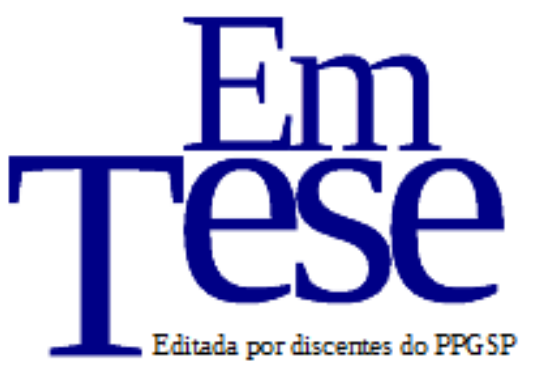

UFSC

PPG SP PROG RAMA DE

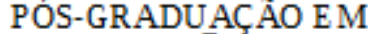

Sociologia

Política

v. 14, n. 1, jan./jun., 2017

\title{
Modernização e Autoconsciência Nacional: a emergência da sociedade pretoriana na reorientação do pensamento de Guerreiro Ramos
}

\author{
Marcelo Tavares Silva ${ }^{1}$
}

\begin{abstract}
Resumo: O artigo faz uma reflexão sobre a evolução do pensamento de Alberto Guerreiro Ramos, identificando a emergência de um certo tipo de pretorianismo social - de acordo com a análise de Samuel Huntington - nos anos de 1950 e 1960 como o elemento definidor de um certo desencanto com o desenvolvimentismo, posteriormente substituído por uma sociologia humanista de caráter crítico da modernização.
\end{abstract}

Palavras Chave: Guerreiro Ramos. Huntington. Pretorianismo. Desenvolvimentismo. Modernização.

Modernization and National Self-Awareness: The emergency of a praetorian society in the reorientation of the thought of Guerreiro Ramos

\begin{abstract}
The article reflects on the evolution of the thinking of Alberto Guerreiro Ramos, identifying the emergence of a certain type of social pretorianism - according to the analysis of Samuel Huntington - in the 1950s and 1960s as the defining element of a certain disenchantment with developmentalism, later replaced by a critical humanist sociology that criticizes modernization.
\end{abstract}

Key Words: Guerreiro Ramos; Huntington; Pretorianism; Developmentalism; Modernization.

\footnotetext{
${ }^{1}$ Doutorando em Ciência Política pela IESP/UERj
} 


\section{Introdução}

O destino de um país é função de sua história e de sua geografia. O Brasil não tem história, que tal nome não merece a série cronológica dos fastos das colônias dispersas, $e$ a sucessão, meramente política, dos episódios militares e governamentais: sua história étnica, econômica e social, só começará a formar-se quando mais estreita solidariedade entre os habitantes das várias zonas lhe der a consciência de uma unidade moral, vínculo íntimo e profundo, que a unidade política está longe de realizar.

(TORRES)

A angústia de Alberto Torres (1865-1917), chancelada por sua passagem de três anos na presidência do Estado do Rio de Janeiro (1897-1900) e pelo posto de Ministro do STF (19011909), encontraria cerca de quarenta anos mais tarde sua mais sofisticada elaboração. Publicado em 1953, O Processo da Sociologia no Brasil (esquema de uma história das ideias) do sociólogo baiano Alberto Guerreiro Ramos (1915-1982) lançava um convite saboroso aos cientistas sociais: "A tarefa essencial dos novos sociólogos parece-me consistir em dar a essa ciência o caráter de instrumento de organização da sociedade brasileira” (RAMOS, 1953, pp.31). Perceba o leitor que os dois autores surgem como balizas de um intervalo especial da história republicana brasileira, no qual desfilaram transformações vertiginosas identificadas por palavras e conceitos que se vulgarizariam: indústria, modernização, sindicalismo, populismo, comunismo, trabalhismo, desenvolvimentismo. Deve-se notar ainda que no exíguo tempo histórico de trinta e nove anos entre A Organização Nacional e O Processo da Sociologia ocorreriam dois golpes de estado (a "revolução de 1930" e o "Estado Novo" de 1945); três Constituições seriam promulgadas (1934, 1937 e 1946); São Paulo tentou se separar da federação (a "Revolução Constitucionalista" de 1932); o Integralismo geraria o primeiro partido de massas do Brasil; uma tentativa fracassada de quartelada comunista (1935); uma ditadura populista organizaria os sindicatos e a industrialização de base; as mulheres passaram a votar; o rádio se consagrou como o principal veículo de informação.

E, se o leitor permitir avançarmos somente até o ano seguinte ao nosso intervalo, já em 1954, Getúlio Vargas cometeria suicídio e seria substituído por Juscelino Kubitschek em 1956, responsável por confirmar a indústria automobilística e uma nova capital no Centro Oeste.

A geração de Guerreiro Ramos a tudo isso assistiu, o que de certa forma explica seu convite esfuziante aos novos cientistas sociais. Aos seus olhos, nunca se experimentara um momento tão sublime, uma oportunidade tão clara, uma conjunção tão perfeita de influências benéficas para se desenvolver uma consciência nacional apartada de uma mentalidade colonizada e mimética de fórmulas estrangeiras. A percepção da aceleração do tempo histórico vinha prenhe de um inescapável senso de responsabilidade por parte das elites intelectuais, os 
combatentes mais fortes ou os representativos - para usar a linguagem de Alberto Torres - cuja missão era domar e interpretar o turbilhão de transformações de forma a garantir, finalmente, a emancipação da nação brasileira do atraso e de sua condição colonial. E, de quebra, desnudar os próceres da ordem anterior, a jeunesse dorée $e^{2}$ (RAMOS, 1961), elite obtusa e descarrilada dos trilhos que então se mostravam prontos a serem percorridos pela nação rumo ao desenvolvimento.

Reinhart Koselleck (1923-2006) escreveu que "pertence à natureza da crise que uma decisão esteja pendente mas ainda não tenha sido tomada” (KOSELLECK, 2006). Aliás, para continuarmos na Begriffsgeschicte ${ }^{3}$, parece que Guerreiro Ramos identificou seu tempo como um tempo de crise, um Sattelzeit - "tempo de sela de novos conceitos" onde o velho desmorona e novo se avizinha. A novidade é que aquele Sattelzeit poderia ser apreendido e traduzido graças ao estado maduro das ciências sociais no Brasil e à capacidade de mobilização que a modernidade garantia. Era um momento de pleno otimismo.

Em consonância ao seu libelo de "cientista social em mangas de camisa", em 1960, depois de fundar o Instituto Brasileiro de Economia, Sociologia e Política (IBESP) e mais tarde o Instituto Superior de Estudos Brasileiros (ISEB), Guerreiro Ramos se filiou ao Partido Trabalhista Brasileiro (PTB). Nas eleições para a Câmara Federal de 1962, conseguiu uma segunda suplência pelo estado da Guanabara o que lhe permitiria ocupar uma cadeira entre agosto de 1963 e abril de 1964, quando teve seus direitos políticos cassados pelo AI-1 partindo, logo depois, para um exílio nos EUA. O desenvolvimentismo que deixara escapar um vislumbre de modernidade brasileira, profetizando emancipação e consciência nacional, tropeçara na ditadura civil-militar.

O que teria dado errado? Os cientistas sociais não foram capazes de decifrar e principalmente orientar a jovem nação quanto os caminhos a percorrer? A elite retrógrada e desafinada resistira? Ou quem sabe o cenário havia sido entusiasticamente analisado, de forma a identificar no próprio projeto de desenvolvimentismo um congênere de certa filosofia da história que assegurava uma resolução inexorável dos problemas nacionais brasileiros por meio da modernização guiada pelos intelectuais?

Quanto a esse último embaraço é que traremos a contribuição do clássico de Samuel Huntington, A Ordem Política nas Sociedades em Mudança, publicado em 1968.

\footnotetext{
${ }^{2}$ A Jeunesse Dorée ou "juventude dourada" é o grupo de intelectuais e políticos que funcionariam como bastiões de uma ordem oligárquica alimentada pela cultura semi-colonial que atravancava o progresso nacional: "O grupo em apreço, por sua situação econômica e social brilhante, exibe, em conjunto, os clássicos traços da psicologia da jeunesse dorée (...) estratos de intelectuais bem nascidos, para os quais as dificuldades materiais propriamente não existem (...) são induzidos a um certo esteticismo diante de si mesmos e da vida, tentando a perfeição interior pela auto análise, pelo esclarecimento, pelo exercício do domínio da vontade e, além disso, pela concepção do homem e da sociedade em termos preponderantemente psicológicos" (RAMOS, 1961, pp.152).

${ }^{3}$ Trata-se da "variante koselleckiana" da história dos conceitos.
} 
Especificamente no capítulo dedicado à análise da sociedade pretoriana, Huntington lança luz à determinados aspectos da modernização experimentada por sociedades latino americanas que não foram contemplados pela sociologia de Guerreiro até seu exílio, mas que curiosamente influenciariam seus textos escritos no exterior e vários aqui publicados no Jornal do Brasil.

Assim, o objetivo desse artigo é contrapor a percepção que Guerreiro Ramos tem do processo de modernização (colhida ao longo de seus escritos entre 1953 e 1963) à análise pessimista que Huntington faz da modernização acelerada experimentadas pelos países do então "terceiro mundo". A aposta é que, combinadas as duas perspectivas, entende-se de maneira objetiva a reorientação do pensamento do próprio Guerreiro em seus anos de exílio, quando o desenvolvimentismo modernizante será substituído por uma sociologia de ideal humanista que coloca na redefinição do homem - e não na modernização desenvolvimentista - a possibilidade de emergência de um mundo novo.

\section{A modernização desenvolvimentista em Guerreiro Ramos (1953-1963)}

Ciência Social é o resultado de consciência crítica, de uma mudança na mentalidade de análise dos aspectos que conferem compreensão e interpretação pragmática do desenvolvimento de uma comunidade. A assertiva de Guerreiro Ramos, logo no primeiro capítulo da Redução Sociológica (RAMOS, 1958), expressava as expectativas em torno da superação de uma "consciência nacional bruta" graças à modernização. Industrialização, urbanidade, formação incipiente da classe operária, consumo - seriam todos operadores da transformação de um caráter nacional até então meramente reflexo de influências importadas num verdadeiro projeto de existência autônoma do Brasil e de seu povo.

Aliás, para o sociólogo baiano, o povo deve se conscientizar - amparado pelos cientistas sociais - das circunstâncias em voga, combinando racionalmente os efeitos da modernização que lhe são dispostos em exegese pragmática, o que faria despertar uma consciência crítica, uma personalidade histórica que o afirma como sujeito de sua própria trajetória liquidando a mentalidade colonial - uma das exigências mais graves da modernização consciente.

O projeto coletivo de construção de uma personalidade histórica assenhorada de sua realidade, substituindo a assimilação literal e pacífica dos produtos científicos importados por métodos de interpretação crítica, é a grande tarefa da Redução enquanto práxis do cientista social comprometido com o seu contexto. Por isso, a Redução exige ainda a sistematização do pensamento e das ideias produzidas anteriormente sobre o Brasil - a elaboração de uma ciência social comprometida com a realidade nacional não começa do nada. Ao contrário, evolui de uma história do pensamento social para a elaboração posterior de um tratado de sociologia e política 
que seja universal em princípios e raciocínios lógicos, mas particular às preocupações nacionais apontando suas soluções. Graças às condições objetivas oferecidas pela modernização, era então possível tomar plena consciência das desvantagens periféricas e do pretenso cosmopolitismo. A nação se personificava e agora conseguia enxergar horizontes definidos, autênticos e específicos de progresso:

A crítica no Brasil, até a presente data, não tem ultrapassado, senão excepcionalmente, os limites do impressionismo. Isso decorre não de uma capacidade intrínseca dos nossos críticos, mas das próprias condições objetivas do país. Até bem recentemente, a nossa estrutura econômica e social não suportava as consequências que poderiam resultar de seu autoconhecimento pois suas contradições eram insolúveis na fase de crescimento em que se encontravam. (RAMOS, 1995, pp.49).

Porém agora, era possível desenhar-se uma sociologia autêntica que para Guerreiro tinha em essência

(...) direta ou indiretamente, um propósito salvador e de reconstrução nacional. Por isso, inspira-se numa experiência comunitária vivida pelo sociólogo, em função da qual adquire sentido (...) Quem diz vida, diz problema. A essência da vida é sua problemática incessante (RAMOS,1995, pp.107).

Esse cientista social autêntico que emergiria do "Sattelzeit" vivido pelo Brasil periférico: um sociólogo/politólogo interessado em compreender e intervir nesse processo, recolhendo contribuições universais mas alimentando a ciência social de "substância brasileira". Se autores como Tobias Barreto, Pontes de Miranda, Tristão de Ataíde, Nina Rodrigues, Arthur Ramos e Gilberto Freyre compartilhavam uma atitude "consular" frente à realidade nacional tratando-a como material etnográfico - "eloquentes documentos de gratuidade e alienação do trabalho sociológico" - a sociologia autêntica é nutrida por autores embebidos da busca por uma consciência de si mesmo, preocupados em se libertar da mentalidade colonial: Silvio Romero, Euclides da Cunha, Alberto Torres e Oliveira Viana, arautos da consciência de que não podemos nos resolver com "a solução dos outros".

Sob tais lentes o autêntico sociólogo perceberia o núcleo mais central dos esforços a serem promovidos: identificar o momento crepuscular das elites políticas tradicionais entorpecidas pelo "exemplarismo cultural" e meras tradutoras para o vernáculo de produtos culturais importados, e substituí-las intelectualmente no campo das ideias e politicamente no campo da representação oficial. Se o momento mostrava a exaustão dos homens e ideias que até então governavam o país, agora anacrônicos em suas posturas e pagando o preço de sua postura mimética, era das classes populares o momento de protagonismo político criador, sempre

\footnotetext{
${ }^{4}$ O que Koseleck e seus colegas da Begriffsgeschichte chamavam de Sattelzeit é o período em que conceitos tomam seu sentido moderno ou pelo menos quando a margem de contestação do significado dos conceitos é bastante limitada. Ao mesmo tempo trata-se de um período de enorme erupção social, um senso geral de aceleração do tempo, além da ideologização e democratização de uma série de conceitos abstratos, o que permitiria um novo tipo de política de massas.
} 
orientadas pelo cientista social seguro de evitar tanto o socialismo quanto o populismo ${ }^{5}$. Uma representação da mesma forma autêntica, que eliminasse a alienação - a distância entre as demandas do "povo massa" e as camadas cultas. Aliás, seria a própria alienação o sintoma mais claro, no nível político, do Sattelzeit brasileiro, objeto fundamental da observação social naquele momento.

Aqui convido o leitor a encarar o otimismo de Guerreiro Ramos. Os cientistas sociais organizados, a reverberação da modernização e seus desafios por instituições como o IBESP e mais tarde o ISEB, a substituição da classe política, atitudes que pareciam configurar um ideal emancipacionista quase inevitável para a sociologia de Guerreiro Ramos. O ingrediente de tensão social e de complexificação do cenário capaz de tornar a alienação incontornável do ponto de vista institucional não aparecia como obstáculo limitador no projeto de Guerreiro. A esse descontrole institucional desacreditado por Guerreiro, Samuel Huntington chamou de hiato, sintoma da modernização terceiro mundista segundo sua análise.

\title{
A "sociedade pretoriana" de Huntington: outra possibilidade de interpretação da realidade brasileira vivenciada por Guerreiro Ramos na década de 50
}

Em A Ordem Política nas Sociedades em Mudança (1968), Samuel Huntington dedica o capítulo três ao conceito de sociedades pretorianas. Segundo o autor,

\begin{abstract}
Usaremos a expressão "sociedade pretoriana" com referência à essa sociedade politizada, deixando claro que a mesma compreende não apenas a participação dos militares mas também de outras forças sociais (visto que) as intervenções militares são apenas a manifestação específica de um fenômeno mais amplo nas sociedades subdesenvolvidas: a politização geral das forças e instituições sociais (...) Os países que possuem um exército político, possuem também um clero político, universidades políticas, burocratas políticos, sindicalistas políticos e corporações políticas. A sociedade como um todo está fora de compasso, não apenas as forças militares (HUNTINGTON, 1975, pp.206).
\end{abstract}

Aqui vale explorarmos a noção de sociedades "fora do compasso". Huntington diferencia "graus de governo" de "formas de governo" - os primeiros relacionados aos níveis de eficiência administrativa, respeito às normas e consciência de pertencimento a uma unidade política. Assim, a diferença entre uma democracia e uma ditadura pode ser menos relevante para a saúde

\footnotetext{
${ }^{5}$ Quanto ao populismo: Para Guerreiro, o remédio à crise partidária é a organização das novas agremiações sob os auspícios da revolução brasileira: "partidos de quadros" passariam a ser "partidos de massa". A política populista, reconhece, fora um avanço se tomarmos em conta a necessidade de superação da política oligárquica. Mas ela própria se desvanece com a auto consciência das massas. Quanto ao socialismo: Guerreiro defende que Revolução é categoria viva, sensibilidade, vivência e projetos concretos. Portanto, não é conhecimento acadêmico. O sociólogo baiano enxergava vários quadros da esquerda nacionalista se pervertendo graças ao comunismo, transformando a retórica revolucionária em instrumento de boçalização da sociedade. O internacionalismo revolucionário seria nefasto pois desnaturaliza em fórmula homogênea as condições nacionais objetivas e realidades específicas.
} 
e preservação do corpo público do que os efeitos percebidos entre comunidades formalmente democráticas, mas onde o consenso, a estabilidade e a legitimidade do governo perante os indivíduos não atinjam um grau de eficiência razoável. A forma democrática, portanto, não instaura de maneira inevitável pressupostos determinantes como o respeito à vida, aos valores de comunidade e às leis.

Na América Latina - assim como em outras sociedades em processo de modernização nos anos de 1960 - a maior carência seria de graus de governo otimizados ou, para usar seus próprios termos, de aperfeiçoamento da autoridade política, resumida nos conceitos de eficiência (resolução de desafios inerentes à modernização), autoridade (respeito por parte dos governados em torno do que é estabelecido pelo governo) e legitimidade (consenso entre os governados).

Da dificuldade em equilibrar a modernização com a resolução das questões envolvendo o trinômio eficiência - autoridade - legitimidade decorreria o hiato salientado pelo autor, definindo países desenvolvidos e subdesenvolvidos politicamente:

\begin{abstract}
A igualdade de participação política (ou a forma democrática) está crescendo muito mais rapidamente do que a arte da associação (ou o grau de governo). As mudanças sociais e econômicas - urbanização, aumento da alfabetização e da educação, industrialização e expansão dos meios de massa - estendem a consciência política, multiplicam as demandas políticas e ampliam a participação política (...) as taxas de mobilização social e de expansão da participação política são altas: as taxas de organização política e institucionalização são baixas. O resultado é a instabilidade política e a desordem (HUNTINGTON, 1975, pp.17).
\end{abstract}

Violências revolucionárias, golpes militares e guerras tribais seriam sintomas indiscutíveis do crescimento da igualdade de participação nessas sociedades, numa velocidade desproporcional à maturação de uma certa "arte da associação". Essa defasagem decorre da morosidade no desenvolvimento das instituições políticas que não conseguiriam acompanhar pareadas a efervescência das mudanças sociais e econômicas. O voto, o jogo pluripartidário e a institucionalidade crescem opacas, ideias mimetizadas sem bases autênticas e funcionais, um corpo estranho alienado e inadequado aos elementos reais que conduzem e direcionam a autocompreensão dessas comunidades. O problema não é mais a liberdade, mas a criação de uma ordem pública legítima.

De outra forma, salienta Huntington, formadas em meio a uma miríade de valores que não elaboraram mas cegamente assumiram (o liberalismo e o socialismo do XIX, a auto determinação dos povos do XX), tais comunidades teriam suas instituições, partidos e vanguardas dialogando com forças sociais inexistentes ou imaturas na arte da associação. Os resultados seriam as oportunistas relações de domínio protagonizadas por grupos de interesses específicos, cuja posse de recursos permite captar o momento e subordinar os demais setores. 
O autor americano salienta que um dos aspectos decisivos da modernidade política é que a existência madura de várias forças sociais em jogo impõe a necessidade de instituições de governo que mantenham relativa independência perante esses grupos, articulando-os de forma pacífica. A força é transformada em direito e a obediência em dever. O diagnóstico de Huntington é que em sociedades complexas, a comunidade é fruto de uma ação política que conceda valor às instituições - estas, em última instância, acabam por expressar o próprio interesse público e não o interesse daqueles que as comandam. Por fim, instituições calcadas em critérios de moralidade, confiança e previsibilidade tendem a racionalizar a autoridade política permitindo complexa variedade de funções, capazes de contemplar toda a pluralidade social e finalmente estimulando - por provocar confiança - a crescente participação política.

Essa não é, portanto, a realidade das sociedades latino-americanas em processo de transformação. Nestas, a modernização tende a gerar alienação e anomia, uma espécie de suspensão das normas, fenda aberta pelo choque entre o velho e o novo. Nesse conflito, os postulantes do novo invadem o cenário de maneira abrupta, indiferentes à capacidade da comunidade de incorporar democraticamente os nascituros valores que carregam. Arrogantes, os grupos de vanguarda deflagram bandeiras incompreensíveis para aqueles com os quais querem falar e conscientizar. Esses valores viram seus emblemas de usufruto exclusivo, contribuindo para a manutenção do alijamento de alguns e subordinação de muitos. Continua a desinstitucionalização, a falta de confiança e de previsibilidade do sistema político.

Chamando Guerreiro Ramos à discussão, os dois autores concordariam diante do fato de que a modernização gera autoconsciência. Entretanto, no caso de Huntington, a falta de associação comunitária propalaria uma autoconsciência de grupo, sectária, munida de interesses próprios e de clara antipatia a outros grupos disputantes. Cresceria um "preconceito de grupo" e consequentemente a violência. Não seria a ausência de modernidade, mas os esforços desordenados e individualistas para alcançá-la que geram a desordem política. Amplia-se a Tese

\title{
do Hiato:
}

\begin{abstract}
A mobilização social é muito mais instabilizadora que o desenvolvimento econômico. $\mathrm{O}$ hiato entre essas duas formas de mudança fornece uma medida para o impacto da modernização na estabilidade política. A urbanização, a alfabetização, a educação, os meios de massa e outros fatores expõem o homem tradicional a novas formas de vida, a novos padrões de prazeres, a novas possibilidades de satisfação. Essas experiências rompem as barreiras cognitivas e atitudinais da cultura tradicional, e promovem novos padrões de aspirações e anseios mas a capacidade de uma sociedade em transição de satisfazer essas novas aspirações aumenta num ritmo muito lento que as aspirações em si. Consequentemente, desenvolve-se um hiato entre aspirações e expectativas (...) esse hiato gera a frustração social (HUNTINGTON, 1975, pp.65).
\end{abstract}

Estar fora do compasso - e aí voltamos à questão que inaugura essa seção - é a característica de uma sociedade mergulhada no hiato. A modernização provoca inevitavelmente participação na política de militares, religiosos, sindicatos - mas o que define uma sociedade 
pretoriana é na verdade a falta de instituições que consigam mediar, refinar e moderar o conflito: "num sistema pretoriano, as forças sociais se enfrentam cara a cara; não há instituições políticas nem grupos nem líderes políticos profissionais reconhecidos e aceitos como intermediários legítimos para moderar os conflitos entre os grupos" (HUNTINGTON, 1975, pp.208). De posse das armas e sob o viés específico de modernização que os alimenta, os militares acabam sendo o grupo de maior poder de eficiência (e não legitimidade) para suspender os conflitos por meio da força - de início como artífices do progresso (o que Huntington chama de passagem de um pretorianismo oligárquico para um radical) e depois como mantenedores do progresso (já no pretorianismo de massa do século XX).

O Brasil à janela de Guerreiro Ramos era uma sociedade em modernização, assumindo seu aspecto de massa. Mas o sociólogo se recusava a aceitar o pretorianismo de massa graças a um irresistível otimismo, de profundas acepções religiosas, que identificava à modernização a ascensão de uma certa ideologia hasteada pelos cientistas sociais e seus arautos políticos, que faria as vezes de solução do conflito e de incorporação institucional das novas demandas de forma a garantir a suspensão do hiato entre modernização e governo, estado e povo - desde que houvesse a necessária ação política.

Essa ideologia convocaria as forças sociais e se propagaria num proselitismo natural até alardear vitoriosa a vitória da autodeterminação. E que ideologia poderosa seria essa, cuja eficiência fascinava Guerreiro Ramos?

\footnotetext{
Há que distinguir dois tipos de teorização da realidade social, isto é, a ideológica ou sociológica. A teorização ideológica é, necessariamente, sectária visto que visa a justificar os interesses particulares de um grupo ou de uma classe (...). A teorização sociológica (...) resulta de uma atitude crítica e autocrítica, radical, interessada em formular uma concepção configurada da realidade social, atenta a todas as tendências que a constituem (RAMOS,1995, pp.61).
}

Não se confunda o leitor com a aparente rejeição de Guerreiro Ramos à palavra ideologia. Trata-se de uma questão de método: ao cientista social autêntico cumpre a teorização sociológica do problema nacional brasileiro, teorização essa resultante da análise crítica de contribuições estrangeiras e reflexões nacionais. Definida a teoria, cumpre torná-la ação. E aqui o surgimento de uma “ideologia orgânica" que impulsione as atitudes práticas por parte do governo e de suas instituições, respeitando os aspectos importantes da revolução em marcha e conferindo-lhes uma direção indutiva. A expansão das classes e do mercado interno, a crise do colonialismo, a coletânea dos esforços via teoria, a sistematização das contribuições fragmentadas, a percepção crítica da alienação e da distância entre a elite política e as novas forças emergentes, a crise da organização partidária... o resultado de todos esses feixes que se cruzam no momento brasileiro dos anos 50 é percepção de que a superação dos entraves 
depende, a partir da teoria da sociedade brasileira, o encaminhamento das forças políticas envolvidas no processo de modernização sob a guia dessa ideologia de ação.

A Revolução Brasileira é a modernização, a destradicionalização. A ideologia é o norte consciente dessa mudança - e essa ideologia é o nacionalismo:

O nacionalismo, na fase atual da vida brasileira, se me permitem, é algo ontológico, é um verdadeiro processo, é um princípio que permeia a vida do povo, é em suma expressão da emergência do ser nacional (RAMOS, 1995, pp.55).

Emerge o povo: a principal força política, operando a Revolução Brasileira e provocando a crise do poder no Brasil. As instituições em funcionamento foram moldadas por um mundo oligárquico que desaparece - e por isso a emergência renovadora de uma política ideológica, pragmática, voltada ao "que fazer?" superando o beletrismo político da jeunesse dorée. A superestrutura fica arcaica diante do turbilhão de transformações que a sociedade e a economia experimentam. O desnível entre o país "legal” e o país "real” só será ajustado se respeitadas as novas forças e interpretadas corretamente pela classe política a ideologia nacionalista que orientam suas demandas. Assim, é a ideologia do nacionalismo bradada pelo cientista social autêntico, munido da vontade de ação e da prudência, que responderá ao momento de encruzilhada brasileira e permitirá rumo seguro à revolução brasileira.

Sabemos que não seria assim. Trazendo nossas observações sobre o texto de Huntington, aqui poderíamos ler "rumo seguro" como a possibilidade de se "esquivar" do pretorianismo de massas, na medida em que feita a equalização e a simetria, as massas seriam justamente o antídoto do pretorianismo. Não foi o que aconteceu. O golpe militar, a cassação do mandato e o exílio nos Estados Unidos fariam Guerreiro revisitar seu otimismo e redefinir o topoi do desenvolvimento modernizante como panaceia da autoconsciência nacional.

\section{Os artigos do exílio: o desencanto com o desenvolvimentismo a ode ao "homem parentético"}

O nacionalismo era para o Guerreiro dos anos 50 e 60 a ideologia dos povos que se libertam de sua condição colonial e assumiram consciência. A soberania, logo, é atributo histórico adquirido pela coletividade num momento revolucionário que fez dessas comunidades, finalmente, universais. O nacionalismo era a única maneira de tornar universalistas os periféricos, sem nunca abrir mão de suas soluções específicas, suas particularidades. Por isso, no Brasil, não era a burguesia mas o povo que conduziria a "revolução brasileira" sob a batuta de uma tecnocracia orientada ao esforço de desenvolvimento. É dela a responsabilidade de uma programação nacional, politicamente idônea através de partidos políticos cuja capacidade política acelere a capacidade econômica. Sim, porque os economistas clássicos se impressionam 
com as formas físicas do capital, mas no caso do Brasil será a vontade o fator central, vontade munida de uma ideologia. Fecha-se o ciclo do raciocínio: a programação econômica em bases nacionais, munida de ideologia, é conduzida pelo pensamento político orientado por padrões civilizatórios (o bem estar da população) de finalidades sociais, ratificando a autonomia da comunidade:

\begin{abstract}
A atual situação econômica do Brasil é definida pelo fato de que as alavancas do seu desenvolvimento estão comandadas por quadros burocráticos e partidários tolhidos por formação teórica e por interesses, de tornar a ação estatal pleno instrumento da acumulação capitalista interna (...). Mas essa deformação de cúpula (...) deve ser urgentemente saneada, o que justifica atenção que lhe damos aqui (...). Nossa situação política é definida pela crise de representatividade dos quadros partidários e governamentais. Crise significa separação (RAMOS, 1960, pp.238-241).
\end{abstract}

O descompasso - aspecto próprio do pretorianismo de massas previsto por Huntington, mas que Guerreiro acreditava evitar caso tivesse sucesso a nova geração de cientistas sociais em "mangas de camisa" - teria como vitorioso o povo brasileiro. É o povo que deve se conscientizar de que é o principal empresário do processo econômico brasileiro, uma entidade que supera particularismos de classe e que deve dirigir o rumo histórico, mesmo que por meio de sua vanguarda, "miniatura do povo" como gostava de falar o sociólogo baiano:

O movimento emancipador popular no Brasil é reconhecido por suas características assim determinadas: é nacionalista, (...) é um movimento de esquerda (...) transcende a realidade exclusiva de toda classe (...) é dirigido pelo povo por intermédio de sua vanguarda. (RAMOS, 1960, pp.251).

O ápice da intervenção de Guerreiro, o elemento central de sua atitude revolucionária, a consagração de sua trajetória teórica - vimos - seria sua vida no parlamento, abortada em 1964. De alguma forma, o pretorianismo de massa que ele esperava evitar (ou pelo menos não conseguia identificar) emergia em seu mais feroz sintoma, o golpe militar. A vanguarda da qual ele se colocava como um dos líderes mostrou-se despreparada. A ideologia do nacionalismo não sobrevivia fora dos corredores acadêmicos, não conseguia contaminar as ruas, era grito que não ecoava. A consciência de comunidade era simplesmente a consciência de alguns que dela pertenciam e percebiam a "revolução em marcha". E 1964 mostrou isso.

No exílio, Guerreiro conclui - agora observando do topo de um país cêntrico - que a verdadeira libertação, o verdadeiro desenvolvimento não seria fruto da ação coletiva organizada, mas, agora, de uma racionalidade crítica que, dialeticamente, derivava historicamente do progresso material e cristalizava-se como uma faculdade específica do indivíduo, tornando-o desobediente diante dos padrões cegos de eficiência industrial. É como se a autodeterminação econômica, antes vista como síntese fosse antes antítese, cuja síntese - e aqui a verdadeira libertação - será o homem parentético: 
(Por tentar ser) autônomo, o homem parentético não pode ser psicologicamente enquadrado como aqueles indivíduos que se comportam de acordo com modelos (...). Ele possui uma consciência crítica altamente desenvolvida das premissas de valor presentes no dia a dia (...) é simultaneamente um reflexo das novas circunstâncias sociais, que agora são mais perceptíveis nas sociedades industriais avançadas (...). Os homens parentéticos prosperam quando termina o período de ingenuidade social. (RAMOS, 1984, pp.7-8)

Num exercício sofisticado de metalinguagem, o otimismo de Guerreiro também se curva às circunstâncias. Se a redenção na década de 50 viria da ideologia nacionalista da modernização brasileira encabeçada pela vanguarda da qual ele acreditava participar, agora os pressupostos de emancipação e autoconsciência assumem novos objetos, novos ambientes e agentes: menos do que a comunidade, mas o resultado dialético (e psicológico) da modernização em cada indivíduo, cada vez mais crítico, soberano e descolado de convenções. Ironicamente, o homem parentético virá da própria sociedade pretoriana de massas, na medida em que - por mais caótico o descompasso entre instituições e povo - o avanço modernizante é mesmo inexorável e com ele o germe de mutação psicológica que definirá o novo homem. Mesmo o trabalhador médio na sociedade pretoriana de massas inevitavelmente perceberia sua vulnerabilidade ao lidar com o ambiente global e integrado do capitalismo, onde a tecnologia - menos do que melhorar sua qualidade de vida - está subordinando-o a ditames que o limitam e o anulam como agente soberano de sua própria condição. É esse incômodo o combustível de uma nova e profunda revolução, o que parece compensar a angústia e a frustração do sociólogo.

Escrevendo em 1978, Guerreiro afirma que no mundo contemporâneo, os resultados deformativos e deculturativos das ideias de modernização e desenvolvimento são mais evidentes justamente nos Estados Unidos - o paradigma da modernização e do desenvolvimento. (RAMOS, 1978). É neste país que as teorias de modernização e desenvolvimento vinculam-se à práticas predatórias nocivas à vida humana e as funções auto restaurativas do ambiente natural (RAMOS, 1978), notadamente o consumo desenfreado e o desrespeito ao meio ambiente:

Este princípio está implícito na distinção que Aristóteles propõe em seu livro Política, entre a riqueza natural e riqueza não natural. A primeira é um meio; a segunda torna-se um fim em si mesma. Explicitamente, Aristóteles considerou a produção de bens e serviços como um meio para o exercício da vida cívica. No que diz respeito aos seres humanos, não é suficiente viver, é imperativo viver bem. Este segundo tipo de vida só é possível no plano cívico. Assim, a vida cívica, um fim em si mesma, ao qual subordinase a produção de bens e serviços. Se, portanto, a produção torna-se um fim em si mesma, a vida cívica se perverte, quando não se anula. Nessa situação, a vida humana torna-se socialmente inviável, se aceitarmos o pensamento aristotélico segundo o qual o ser humano só se realiza propriamente como animal político. (RAMOS, 1978)

Uma possível aposta, então, para fecharmos o texto: independente das instituições que os governam, os homens da sociedade industrial tem na tecnologia o fator principal responsável para que eles próprios experimentassem a necessidade de uma nova revolução, direcionada a 
estilos de vida cada vez mais parentéticos ${ }^{6}$, e por conseguinte, libertários. Fracassado o projeto dos anos 50, a sociologia de Guerreiro se atualiza e confirma seu otimismo.

"O "Homem Parentético" tudo questiona, eivado de um ideal humanista. É parentético porque consegue se colocar "entre parênteses" e rejeita se subordinar à rotinas burocráticas, tanto de trabalho quanto políticas. A emergência de homens parentéticos é própria de uma sociedade que percebe a superação da escassez pela abundância, e por isso consegue se desamarrar dos valores próprios da era do capitalismo modernizante. 


\section{Referências}

HUNTINGTON, Samuel P., A Ordem Política nas Sociedades em Mudança, São Paulo, Forense Universitária/Ed. USP, 1975

KOSELLECK, Reinhart, Crítica e Crise, uma contribuição à patogênese do mundo burguês, Rio de Janeiro, UERJ/Contraponto, 1999

RAMOS, Alberto Guerreiro

. Redução Sociológica, Rio de Janeiro, Ed. UFRJ, 1996

. O Problema Nacional no Brasil, Rio de Janeiro, Saga, 1960

. Modelos de homem e teoria administrativa, in Clássicos da Revista de Administração Pública, abril/junho de 1984

Limites da Modernização (artigo), Jornal do Brasil, 22 de junho de 1979, pp.32 da UFRJ,1995

Introdução Crítica à Sociologia Brasileira, $2^{a}$. Edição. Rio de Janeiro, Editora O Processo da Sociologia no Brasil (esquema de uma história das ideias), Rio de Janeiro, Estúdio Artes Gráficas, 1953

. A Crise do Poder no Brasil, Rio de Janeiro, Zahar, 1961

TORRES, Alberto, O Problema Nacional Brasileiro, São Paulo, Companhia Editora Nacional, 1978

\section{Bibliografia Secundária}

AZEVEDO, Ariston. A sociologia antropocêntrica de Guerreiro Ramos. Tese de doutorado. Florianópolis, UFSC. 2006.

BARIANI, Edison. Guerreiro Ramos e a redenção sociológica: capitalismo e sociologia no Brasil. São Paulo, EDUSP, 2011.

LYNCH, Christian C. E, Teoria pós-colonial e pensamento brasileiro na obra de Guerreiro Ramos: o pensamento sociológico (1953-1955), Cadernos CRH vol.28 no.73 Salvador Jan./Apr. 2015

MAIA, João Marcelo Ehlert. Reputações à brasileira: o caso de Guerreiro Ramos. Sociologia \& antropologia v. 2, n. 4, p. 265-291, 2012.

OLIVEIRA, Lúcia Lippi. A sociologia do Guerreiro. Rio de Janeiro: Editora da UFRJ, 1995. 